\title{
EMPIRICAL PERSPECTIVE OF INDUSTRIAL INVESTMENT FUND FOR LOCAL GOVERNMENT SUSTAINABILITY IN HENAN, CHINA
}

\author{
Zhang Li ${ }^{i}$, \\ Jacquline Tham, \\ S. M. Ferdous Azam \\ Postgraduate Centre (PGC), \\ Management and Science University, \\ University Drive, Off Persiaran Olahraga, \\ 40100 Shah Alam, Selangor, \\ Malaysia
}

\begin{abstract}
:
To facilitate China's economic reform, the rapid growth of the industrial fund has become a vital support force. This study aims to evaluate the Local Government's Industrial Investment Fund Sustainability in Henan, China. Two-factor theories, quasi-public theory, market failure theory and sustainable development theory, along with a study of domestic studies on the development of local government industrial investment funds, were addressed to investigate the research phenomenon empirically and theoretically. For this analysis, quantitative methods are considered to be more fitting. The primary goal is to provide an overview of the apparent facts of interest to researchers. The quantitative findings include primarily statistical analysis of the data obtained. In this study, the description of statistical analysis data is used to explain the studies predicted final results. The empirical findings of this study that the structure of the supervisory system, the process of market exit and technical talents are essential factors that stimulate the industrial investment fund of the people for the local government in Henan, China, are similar and confirm with the results of previous scholars. Thus, the primary catalyst for China's financial growth is accountability. There would be no China today without a transition and an opening. Nevertheless, in comparison to the real needs of monetary gain, China's receptiveness to the outside world is still insufficient.
\end{abstract}

JEL: L10; L16; L78

Keywords: industrial investment fund, local government, sustainability, Henan, China

i Correspondence: email 751074758@qq.com 


\section{Introduction}

The industrial investment fund is a specific phenomenon in China and is generally referred to abroad as a venture capital fund and private equity fund. In developing countries, an industrial investment fund has become the nucleus of the financial system. This is typically targeted at unlisted companies with a high potential to invest in equity (Yu et al., 2014; Shi, 2016; Azam and Moha Asri, 2015; Tham et al., 2017; Udriyah et al., 2019). Local government industrial investments funds in China are currently not only facing sufficient room for growth but will also play an increasingly important role in the development of the national economy (Zhang et al., 2008; Yu, 2016). Henan faces both great opportunities and challenges, according to Yinxing (2016), and the growth of different cities in Henan Province is significant. In addition, the industrial investment fund, as a medium, plays a vital role in developing the local economy better (Luigi and Sorin, 2009; Luther et al., 2005; Maxwell and Delaney, 2004). In 2017, with 45 new investment guidance funds, with an additional target of 221.5 billion yuan, the most important number of new government industrial investment guidance funds are in East China; the largest target size of the new investment guidance fund is North China, with 14 new investment guidance funds, with an additional target size of 345.2 billion yuan; the number of new investment guidance funds (The National Bureau of Statistics of China, 2019). Huang (2018) reported that 546 government industrial investment guidance funds were set up in East China by the end of June 2018, with a total target size of 2,174.7 billion yuan, ranking first in the country in terms of quantity and target size; the overall target size of the North China government-industry investment guidance fund is 1,554.1 billion yuan, which is the second largest in China (The National Bureau of Statistics of China, 2019).

According to the CITIC Research Institute's survey report, the role of government industrial investment fund managers in investment decision-making According to the survey report, $26 \%$ of government industrial investment fund managers have the attitude of not joining the fund's decision-making committee and not taking decisions on the subinvestment. fund's However in order to protect the fund's policy of direction and maintain the right to a one-vote veto, 44 percent of them prefer to invest in a sufficient proportion of the follow-up transaction. In addition, the percentage of those who do not engage in fund management matters and who do not follow-up investment accounts for 4 percent, and those who choose to join the decision-making board account for 26 percent (The National Bureau of Statistics of China, 2019). Each region formulates main investment directions of local government investment funds in accordance with its location benefits and industrial development strategies.

There are two common public investment fund models, one of which is a parallel investment mode, and the other is a formal investment mode. The parallel investment model is distinguished by the absence of preference and inferiority structures between government and financial institutions, carries the same risks and benefits and has a consistent structure, is ideal for guiding investment by parent funds with a 
straightforward profit model and is specifically placed, e.g. by the parent fund, which is especially supportive of mixed state reform.

In the case of Henan Province, according to the Ministry of Finance "Interim Measures for the Administration of Government Investment Funds" (Budget, 2015), the Government of Henan Province "Opinio" (Budget, 2015). In order to speed up the operation of government investment funds, boost the effectiveness of the use of financial funds and encourage the sustained and healthy growth of government investment funds, the committee and government of the Henan Provincial Party attach great importance to the growth of private investment funds. Policy documents to encourage the growth of venture capital and industrial investment funds have been released for three consecutive years, and the Development Fund should be regarded as an important way of encouraging the direct funding of real companies and facilitating the convergence of business and finance. To help and encourage the industrial agglomeration of private investment funds, the Central Plains Fund island should be built and developed. The Henan Government Investment Fund also expanded to 108 venture capital companies and 236 equity investment companies from only a government-funded venture capital fund and no equity investment fund before 2012 (Michaelas et al., 1998, 1999; Chen, 2011; China Venture Capital Institute, 2012; Qing Research Center, 2018).

In the financing process, Henan Province is restricted by high costs and limited channels, with many barriers, such as financing through the issuance of corporate bonds and bank loans, leading to high costs and difficulties in financing. Therefore, as an efficient investment and financing mechanism, the production and enhancement of the Henan Industrial Investment Fund has important practical significance for the enrichment of business financing networks, the alleviation of company financing difficulties, the guidance and optimization of the regional industrial structure and the improvement of the capital market. In addition, because of overcapacity and economic downturn, whether listed companies with several funding networks or relevant functional divisions, the skill and incentive of direct investment in related industries are insufficient, investors are more likely to invest by setting up suitable industrial investment funds and competent management teams in order to achieve the target (Dewi et al., 2019; Nguyen et al., 2019; Maghfuriyah et al., 2019; De Silva et al., 2017; Kuruwitaarachchi et al., 2019; Pambreni et al., 2019).

The government's industrial investment fund is highly organised and sophisticated in its internal nature (Rachmawati et al., 2019; Azam and Yusoff, 2020; Azam et al., 2020). Via various transaction designs, it can absorb and incorporate the benefits of the conventional industrial investment mode. It will boost not only the productivity of industrial investment, but also better manage risks, replacing the current government platform companies to some degree. At the same time, its versatile form has unique supervisory avoidance advantages and has more creative capital operating capacity than the conventional model. Besides, after the fund ceases to operate and investors withdraw, it will leave high-quality project platform companies for local governments, which is conducive to local governments to re-integrate project resources 
and improve the efficiency of investment and financing (Azam et al., 2014; Haur et al., 2017; Katukurunda et al., 2019; Chun et al., 2019; Yang et al., 2019).

Following the large-scale development of the Local Government Industrial Investment Fund's structured investment and financing mode, on the one hand, under the new normalisation of the economy and the gradual decline of local fund budget revenue, it will become an essential means of promoting local GDP and will play a more prominent role in promoting related primary and upstream and downstream industries. Therefore, in order to promote the transfer of employment from the primary industry to the secondary and tertiary sector, it will reduce the price of labour and other factors in the market and bring positive changes to industrial development.

\section{Literature Review}

The American behaviourist Frederick Herzberg first proposed the two-factor theory (Motivator-Hygiene Theory) in 1959. Herzberg Motivator-Hygiene and find that those who can consciously carry jobs, happiness and reward factors called "incentives", such as the awareness and achievement of self-value, appreciation, and the growth of the excellent space production factor can stimulate the excitement of employees. It only plays the role of eliminating satisfaction when staff have no objection to these variables but does not play the role of motivating staff. In Maslow's hierarchy of needs theory, such considerations are analogous to the most basic physiological needs, protection requirements, emotional needs and other lower needs. Improving the "hygiene factor" can only decrease employee frustration, but it cannot play a motivating role. We must pay attention to the "motivation factor" to promote the individual effort of employees. The excitement of its members is the primary motivation and essential factor for the realisation of organisational objectives for every organisation.

Hume first suggested the concept of public goods, which was governed by PA Samuelson in 1954, in Quasi-Public Philosophy, his theory of human existence in 1739. PA Samuelson (1954) pointed out that "goods can, according to their competitive and exclusive features, be divided into public goods, private goods and mixed goods." Between private goods and pure public goods, available mixed goods, also known as quasi-public goods, constitute a specific commodity. It has limited non-competitiveness or non-exclusivity, generally speaking. Finite non-competitiveness is the principle that the consumption of an individual contributes to the decline of the consumption of the rest of society, however, the smaller part of that is not entirely reflected by price; however, restricted non-exclusivity refers to the fact that the consumption of other people would be influenced by personal consumption of public goods, usually implying a decline in the consumption of others. Information processing became more convenient with the exponential growth of information technology. As a commodity, technological advancement is quickly imitated and learned by other firms. Such imitation does not require additional innovation costs, nor does it cost any less than the cost of scientific discovery and the company's invention, which is expressed as free goods. Based on the 
above review, technological innovation, as a quasi-public product requires the intervention of the government to avoid the emergence of market failure.

Furthermore, market failure refers to a phenomenon in which the activity of the market cannot reach equilibrium within the economic structure of the market, so that the market cannot play its part in maximising the distribution of resources. Business mechanisms and market failures are among the causes of market failure. Defects can only be accomplished by the visible hand of the government in order to interfere to reach the optimal market.

Lucey and Dowling (2013) found that the funding difficulty of start-up companies is the most prominent issue, which depends primarily on the presence of the phenomenon that on the one hand, the cost of start-up companies is higher, and the liquidity and liquidity of the funds are reduced due to the long term of venture capital. The funding challenges of companies in the seed stage and start-up stage are therefore very prominent. Venture capital has seen exponential growth in the country to some degree with the establishment of venture capital law in China and the attention of the state; alleviating the funding difficulties of start-up companies. In setting up the guiding fund, governments at all levels in our country specifically need the lowest investment proportion. The funding problems of start-up companies are increasingly being addressed through the administrative guidance of the government. On the one hand, the venture capital advice fund of the government is primarily concentrated in the eastern coastal areas because of the disparity in the degree of economic growth.

The philosophy of sustainable growth, on the other hand, is a modern paradigm of development for contemporary human beings. "It is realised by reflecting on the production and living behaviour of human beings and worrying about reality and the future when the world faces three major economic, social and environmental problems." The United Nations Conference on Environment and Development held in Rio de Janeiro, Brazil, since 1992, developed sustainable development as a popular human society strategy, the theory of sustainable development. Research on the theory of sustainable development in China has been on the rise in recent years. From the viewpoint of practise, some scholars conclude: "Sustainable development is the co-ordinated interaction of politics, economy, culture and ecological nature; its essence is the sustainable development of the practise and practical ability of human production" (Reid, 1996; Riportella and Martínez, 2003; Ross, 1977; San and Heng, 2011; Seifert and Gonenc, 2008; Taylor, 1990; Ying et al., 2016). Indeed, the philosophy of sustainable development has given us a new level of thought and way of thinking It includes rich ideological connotations and deep philosophical ideas and encourages people to evolve from the co-ordinated growth of the ecological environment and economic development to the development of economic, industrial, cultural and human social activities. In China, the sustainable development of local government industrial investment funds has drawn the attention of scholars: economic development is the centre of sustainable development. Edward B. Barbier describes sustainable development in the book, Economics, Natural Resources, Insufficiency and Development, as "optimising the net benefits of economic development while preserving the quality of natural 
resources and the services they provide". "Economic development is the main way of establishing the concept of sustainable development" and "sustainable economic development itself "should be the main material and the first area of the strategy for sustainable development.

To promote China's economic reform, industrial upgrading and innovation and entrepreneurship growth, the rapid development of the industrial fund has become a vital support force. However, industrial funds are also facing many obstacles in the growth process, such as speculative arbitrage, open-ended real debts, withdrawal difficulties, and government industrial funds' development difficulties. Therefore, it is important to correct the misalignment of industrial funds, to reinforce adequate management, to improve the quality of workers, to improve the self-disciplinary structure of industry, to ensure the stable growth of industrial funds over the long term, and to encourage the enhancement of the financial system and the creation of financial resources. Currently, for the creation of local government industrial investment funds in China, research finds that the key achievements are as follows: the imperfect regulatory system, the imperfect business exit mechanism, the absence of experts, the absence of risk reduction and the portfolio of single funds.

Previous research also confirms the evidence and the value of improving the monitoring of the operation of the fund by industrial investment funds in order to avoid the possibility of market failure. In order to prevent the depletion of the capital of the industrial investment fund due to human factors, the government should take part of the restricted financial funds to invest in the industrial investment fund, so it needs to take the requisite steps to improve the regulation of the capital risk of the industrial investment fund. In addition, we should create and perfect a strict approval mechanism in the follow-up production of industrial investment funds, establish a diversified fund market, encourage companies to innovate and shape different financial derivatives, enhance market regulation of financial derivatives, and learn from advanced international experience to boost the development of Chinese funds, but we can't. We should learn from the domestic conditions of China and establish good external conditions for the smooth operation of the market for industrial investment funds (Peng and Lai, 2012; Rajan and Zingales, 1995; Rao et al., 2007; Wang et al., 2014). Most of the guiding funds however have poor performance assessment knowledge and have not developed a formal performance assessment framework. The provision of knowledge support for the production of the assessment of financial expenditure benefits is difficult. Generally speaking, China has not yet developed a Scientific and Unified Performance Assessment System for Government-Guided Funds or a similar financial expenditure benefit assessment system that is not conducive to the timely identification and prevention of financial risks (Miles and Shevlin, 2001; Mira, 2002; Norton, 1991; Norvaisiene, 2012; Paul et al., 2007; Zhao, Chan \& Song, 2017). The explanation for this is that the establishment and approval of directed industrial investment funds by the Chinese government is subject to multiple scrutinies and the absence of a single regulatory body. The headquarters of the People's Bank of China and the associated 
exchanges (Shanghai Stock Exchange, Shenzhen Stock Exchange and other regional trading centres) are responsible for setting up and authorising industrial investment funds, for example. At present, the fund's self-regulatory organisation, such as the compulsory creation of the Management Committee of the Industrial Investment Fund, has not been put on the agenda.

Consequently, regulation of industrial investment funds is not yet unified, so there is a lack of adequate management (Liu, Zhang \& Hu, 2006). Therefore, in order to improve monitoring, the following steps should be taken: First it is possible to create a functioning coordination community effectively. It is made up of 12 divisions, including Municipal Credit, State Capital, Growth and Reform, Commerce, Agriculture, Science and Technology, Culture, Tourism, Small and Medium-sized Business Industry and Trade, Economics and Finance, each of which is responsible for its responsibilities. To ensure the efficiency and protection of fund use through joint study, collaborative decision-making, strict control of project planning, strict control, and direction of fund feedback. Secondly, in planning and development, the Finance Office will take the lead, and the Finance Office will serve as the investor for the government. The three are to set up a committee of review experts, consisting of members of industrial technology, experts from private equity funds and responsible units of industry. It is responsible for evaluating the particular fund set up by the Guiding Fund and private investors. Fourthly, a Project Investment Decision-Making Committee should be formed to set up a Project Investment Decision-Making Process under the oversight of industry experts from relevant fund organisations and departmental observers. "To whom to invest" is no longer the decision-making of the government, but a decision to let "professional individuals do professional things" for professional managers who are more familiar with business rules and project prospects (Huang, 2016b). Intermediaries in the international equity investment industry include specialist intermediaries involved in appraisal, ranking certification and assurance, but their growth in China is still in its infancy. The quantity and efficiency of these intermediaries is not adequate to sustain the industrial investment fund demand in China. In addition, different types of businesses, investment banks, commercial banks and other institutions are more prevalent and mature, but are primarily targeted at stocks. The right investment market service was established at a late stage, lacking relevant expertise and remaining on the service floor, which is not conducive to the growth of the entire equity investment market. The current institutional conditions of China cannot represent the equity investment market very well, whether from the perspective of specialist or general intermediaries. The growth of the market has been significantly hindered, whether by experience, quality or performance, and needs to be reversed, strengthened and stimulated (Zhang, 2008; Kaplan and Norton, 2012; Li et al., 2009, 2011; Lisboa, 2017). 


\section{Materials and Methods}

This study examines a set of research hypotheses based on quantitative data collected from questionnaires to establish a theory to verify the hypothesis, rather than trying to establish a theory. Therefore, quantitative methods are considered to be more suitable for this study. The primary objective is to provide researchers with a description of the apparent facts of interest, which will cover the necessary statistical data needed for these studies; the average, standard deviation, frequency and pattern are among them (Sekaran and Bougie, 2016). Quantitative results mainly involve statistical analysis of collected data. Then these data are analysed to achieve the purpose of the study. In this study, the data interpretation of statistical analysis is used to describe the expected final results of the study clearly. Therefore, the quantitative research method is adopted as the main design in this study, which is most suitable for this study. This study follows a probability model, which was determined by previous studies. Positivists believe that the results of one study can be extended to another similar study, whether it is conducted in different environments and circumstances (Pallant, 2011; Pandey, 2004; Peel and Wilson, 1996; Zikmund, 2003; Saunders and Thornhill, 2009). Therefore, the paradigm of this study belongs to the "positivist" approach. The questionnaire of the present study based on the existing literature and past researches regarding student satisfaction in different contexts. In designing a questionnaire, the researcher should focus on three main areas, first is the wording of the questions while the second relates to categorising, scaling and coding of the responses. Thirdly, the general appearance of the questionnaire is also essentially the same as the other two, because these facilities to minimise the bias in research. In wording, five factors have been proposed to be considered by Sekaran \& Bougie, (2014): as 1) "the appropriateness of the content of the questions", 2) "how questions are worded and the level of sophistication of the language used", 3) "the type and form of questions asked", 4) "the sequencing of the questions", 5) "the personal data sought from the respondents" (p. 198). Secondly, the researcher should focus on the principles of measurement, which emphasise on what scales and scaling techniques to be applied in measuring each concept - however, appropriate scales to be employed depending on the type of data to be required. Lastly, the general appearance of the questionnaire is also essential to address the wording and measurement in the questionnaire. Sekaran and Bougie (2016) pointed out that the neatness and attractiveness of the questionnaire with proper introduction, instructions and logically organised set of questions serve opportunities that more accessible the respondents to answers. Based on the constraints such as time, cost, practicality and also reviews of existing research (Kothari, 2004), the researcher in the present study, choose to use the back-translation procedure in order to the translation of the questionnaire. 


\section{Findings}

There were 520 valid questionnaires were finally used for the purpose of this study after removing any extensive missing data, biased as well as outliers. Through analysis of the demographic, it was found that majority of the respondents with between 18 to 45 years old, dominated by males which is $59 \%$ and who are mostly professionals working either in the private sectors or government sectors with minimum a degree qualification.

Initially the KMO test that measures the sampling adequacy stipulated 0.955 . Hence, the sample size is adequate (Kothari, 2004). Moreover, Huang (2016b) recommended 0.5 as a minimum $\mathrm{KMO}$ value and also designated values above 0.9 as superb. Apparently, Bartlett's test of sphericity posits a $\mathrm{p}$ value of less than 0.05 which indicates that the factor model is appropriate. Interchangeably, it rejects the notion that the correlation matrix is an identity matrix (Kline, 2011). The scree plots the eigenvalue against the factor number. From the eighth factor onwards, the line is nearly smooth demonstrating that the successive factors proclaim trivial amount of the total variances.

Using the total variance explained as a, the initial number of factors retained is five factors. Perhaps, the number of rows in Extraction Sums of Squared Loadings will give a better jaw line of the factors. Moreover, initial eigenvalues itemized that all factors are standardized. Conjointly, the Rotation Sums of Squared Loadings represents the promulgation of the variance after the Promax rotation that forces near zero coefficients to approach zero faster than coefficients further from zero which is disseminated over the seven extracted factors (Kline, 2011).

The Promax oblique rotations method unmasked a pattern matrix uncovers the very significant factor loadings which revealed that there are five factors whereby absolute values above 0.5 are considered (Hair et al, 2007). As a matter of fact, six factors were anticipated. Interestingly, items of Supervision system structure and Market exit mechanism loads together. The same scenario is visible in Policy towards Using and Sustainable development. Accordingly, Confirmatory Factor Analysis is conducted yielding Normed chi-square and RMSEA values that are incoherent with the threshold values. However, CFI value divulged an incremental fit. Upon diagnosis of the Modification Indices, it is discerned that the association of e4 and e5 is more than 15 . On that account, it is essential to re-specify the model correlating these residuals by embossing a double-headed arrow. The modified measurement model for lack of risk prevention construct is acceptable (Chi-square/df $<5, \mathrm{CFI}>0.9$, RMSEA $<0.08$ ). All the factor loadings are $>0.5 \&$ AVE is $63 \%$. In relation to multivariate normality, Mardia's critical ratios was more than 5 (22.911) whereby multivariate normality is not satisfied. By virtue of 1000 bootstrap sample, the Bollen-Stine $p$ value of 0.113 is more than 0.05 . Thus, the model correctness is congruous.

Uniformly, there are 5 items in this construct. The maximum correlation of each item with at least one other item in this construct is encompassed by of 0.3 and 0.9 . Thus, all the 5 items correlate adequately. The skewness and kurtosis of all the items are within the preferred magnitude propagating univariate normality of the data. 
Accordingly, Confirmatory Factor Analysis is conducted yielding Normed chisquare and RMSEA values that are not enclosed within the threshold values. However, CFI value uncovered an incremental fit. Upon verification of the Modification Indices, It is unfolded that the association of e 4 and e 5 is more than 15 . Hence, it is preeminent to re-specify the model correlating these residuals by molding a double-headed arrow.

Therefore, the modified measurement model is scanned through that unearthed a more noteworthy absolute fit and parsimonious fit whereby the modified measurement model for Single fund portfolio construct is acceptable (Chi-square/df $<5, \mathrm{CFI}>0.9$, RMSEA $<0.08$ ). All the factor loadings are $>0.7 \&$ AVE is $74 \%$. In respect to multivariate normality, Mardia's critical ratios was more than 5 (23.61) whereby multivariate normality is not satisfied. By virtue of 1000 bootstrap sample, the Bollen-Stine $p$ value of is 0.258 more than 0.05 . Thus, the model correctness is harmonious. Persistently, there are 5 items in this construct. The maximum correlation of each item with at least one other item in this construct is betwixt of 0.3 and 0.9 . Thus, all the 5 items correlate sufficiently. The skewness and kurtosis of all the items are within the adequate leverage disseminating univariate normality of the data.

Accordingly, Confirmatory Factor Analysis is conducted yielding CFI value that is within the threshold values. However, Normed chi-square and RMSEA values are not within the threshold confines. Upon checking the Modification Indices, it is spotted that the association of e 4 and e 5 as well as e 1 and e 5 is more than 15 . Hence, it is meaningful to re-specify the model correlating these residuals by outlining a double-headed arrow. On the road to multivariate normality, Mardia's critical ratios were more than 5 (47.969) whereby multivariate normality is not satisfied. By virtue of 1000 bootstrap sample, the Bollen-Stine $\mathrm{p}$ value of is 0.181 more than 0.05 . Thus, the model correctness is concordant. Proportionately, there are 5 items in this construct. The maximum correlation of each item with at least one other item in this construct is encompassed by of 0.3 and 0.9. Thus, all the 5 items correlate adequately. The skewness and kurtosis of all the items are within the preferred magnitude enforcing univariate normality of the data.

Accordingly, Confirmatory Factor Analysis is conducted yielding Normed chisquare and RMSEA values that are not within the threshold values. However, CFI value administered an incremental fit. Upon inspection of the Modification Indices, it is spotted that the association of e 4 and e 5 is more than 15 . Hence, it is paramount to re-specify the model correlating these residuals by fashioning a double-headed arrow. Without exception to multivariate normality, Mardia's critical ratios were more than 5 (37.117) whereby multivariate normality is not satisfied. By virtue of 1000 bootstrap sample, the Bollen-Stine $\mathrm{p}$ value of is 0.536 more than 0.05 . Thus, the model correctness is harmonious. After conducting the CFA for measurement models in each variable in the conceptual framework, the combined measurement model is constructed to test the composite scores.

Bagozzi and Yi (1988) sanctions composite reliabilities of greater than 0.60 is satisfactory. Thus, that being the case, composite reliabilities of all the constructs is satisfactory. Similarly, average variance extracted of more than 0.50 is essential. 
Consequently, the average variance extracted of all the constructs is significant. Discriminant validity is evaluated to ascertain the scale to which items or constructs are different. At the item level, discriminant validity is prevailed when an item correlates highly with items within the construct it envisions to evaluate greater than items affiliated to other constructs (Barclay, Higgins and Thompson, 1995). In this study, discriminant validity at the item level was found to be acceptable. This is also proven via the pattern matrix discussed in earlier sections.

At the construct level, discriminant validity is present when the variance shared between a construct with other construct in the model is less than the variance within that construct itself (Fornell, Tellis \& Zinkham, 1982). Discriminant validity is substantiated as the new diagonal elements are greater than are all corresponding construct correlations except Sustainable development and Policy in which the correlation between these two constructs is 0.900 which is high but still within 0.3 and 0.9 which is still acceptable. This is in line with the pattern matrix of EFA whereby items of policy towards using and sustainable development load together. Respondents with positive policy in view of industrial investment fund for the local government in Henan, China will display a positive trend in their sustainable development it too. Hence, in this study, discriminant validity at the construct level was found to be admissible.

In testing for multivariate normality, Mardia's critical ratio was 101.545 (more than 5). Hence, multivariate normality assumption is not met. Therefore, in the estimation of the coefficients, the bootstrap method was used. Besides that, there is a significant impact $(B=0.266, \mathrm{p}<0.05)$ of Professional talents on Policy. The $95 \%$ confidence interval for Professional talents is [0.153, 0.369] whereby the value 0 does not fall within the interval, by and by indicating Professional talents is a significant predictor.

In addition, there is a significant impact $(B=-0.136, \mathrm{p}<0.05)$ of Single fund portfolio on Policy. The 95\% confidence interval for Single fund portfolio is [-0.226, -0.046] whereby the value 0 does not fall within the interval, in like manner indicating Single fund portfolio is a significant predictor. Furthermore, there is an insignificant impact $(B=-$ 0.077, $\mathrm{p}>0.05$ ) of Lack of risk prevention on Policy. The $95 \%$ confidence interval for Lack of risk prevention is [-0.173, 0.018] whereby the value 0 does fall within the interval, further indicating Lack of risk prevention is an insignificant predictor. Intriguingly, there is a significant impact $(B=0.873, \mathrm{p}<0.05)$ of Policy on Sustainable development. The $95 \%$ confidence interval for Policy is [0.834, 0.912] whereby the value 0 does not fall within the interval, again indicating Policy is a significant predictor.

\section{Conclusion and Recommendation}

The empirical findings of this study that the structure of the supervisory system, the process of market exit and technical talents are important factors that stimulate the industrial investment fund of the people for the local government in Henan, China, are similar and confirm with the results of previous scholars. For quite a while, China has been under an arranged monetary system. So far while the structure of the financial 
framework of the communist market has been initially resolved, the notion of an arranged economy is still influenced in several respects. For example, an excessive number of regulatory endorsement activities results in an excessive access limit for creative undertakings and the absence of real cutting-edge undertakings, which is an offsite presentation of government capabilities. The Chinese government has announced to reduce authoritative evaluation and endorsement after China's increase to the WTO to complete the shift in government works. The main catalyst for the financial growth of China is accountability. There would be no China today without a transition and an opening. Nevertheless, in comparison to the real needs of monetary growth, China's receptiveness to the outside world is still insufficient. For example, the wellspring of China's industrial speculation fund is not adequate, the size is small in view of the fact that the fundamental source relies on the legislature at present, and the money-related assets of the administration are negligible. If China's receptiveness to the outside world is further strengthened, the growth of the capital market will advance dramatically. For example, annual studies show that Israeli industrial venture money from U.S. financial specialists. Industrial venture funds in China start from remote capital. If we increment the level of opening to the outside world and effectively present external capital, we can incredibly fortify the quality of industrial speculation funds without the marvel of deficient supply.

\section{References}

Azam, S. M. F., Mohd Shukri, S., \& Ab Yajid, M. S. (2020). The impact of dynamic factors on the successful implementation of SAP. International Journal of Psychosocial Rehabilitation, 24(7), 5366-5376. https://doi.org/10.37200/IJPR/V24I7/PR270497.

Azam, S. M. F. and Moha Asri A. (2015). Differential Roles between Owner and Manager in Financial Practice That Contributes to Business Success: An Analysis on Malaysian Small Business, Academic Journal of Interdisciplinary Studies, 4 (1 S2): 123134.

Azam, S. M. F., \& Yusoff, S. K. M. (2020). Investment and financing analysis of automotive industry of China. International Journal of Psychosocial Rehabilitation, 24(7), 4848-4857. https://doi.org/10.37200/IJPR/V24I7/PR270464

Azam, S. M. F., Haque, A., Sarwar, A. and Anwar, N. (2014). Training Program Effectiveness of Service Initiators: Measuring Perception of Female Employees of Bank Using Logistic Approach, Asian Research Journal of Business Management, 1 (2): 98-108.

Chen, L. (2011). How the pecking-order theory explain capital structure. Journal of International Management Studies, 6, 1-9.

China Venture Capital Institute (2012). 2012 China Venture Capital Yearbook. Shenzhen: China Venture Capital Institute. 
Chun, L., Tham, J. and Azam S. M. F. (2019). Corporate Competence Determining Factors in China Telecom Industry in Achieving Customer Satisfaction, European Journal of Management and Marketing Studies, 4 (3), pp.75-101.

De Silva, A. D. A., Khatibi, A. and Azam, S. M. F. (2017). Do the Demographic Differences Manifest in Motivation to Learn Science and Impact on Science Performance? Evidence from Sri Lanka, International Journal of Science and Mathematics Education, 16(S1), 47-67.

Dewi, N., Azam, S. M. F. and Yusoff, S. K. M. (2019). Factors influencing the information quality of local government financial statement and financial accountability, Management Science Letters, 9 (9): 1373-1384

Edward \& Khawari (2016, July 8). GST has not helped, says SME association. Malay Mail Online. Retrieved from http://www.themalaymailonline.com/

Hair, J. F., Money, H. A., Samouel, P. \& Page, M. (2007). Research Methods for Business. England, John Wiley and Sons Ltd.

Haur, C. H., Khatibi, A. and Azam, S. M. F. (2017). Antecedents of Consumers' Perception towards Online Advertising in Malaysia: The Structure Equation Modeling Approach, European Journal of Management and Marketing Studies, 2 (3): 15-30

Huang T., (2018). Economic theory innovation and China's development practice, China Political Economy, Vol. 1 Issue: 1, pp.55-66,

Huang, T. (2016a). Building contemporary Chinese Marxist political economics, China Review of Political Economy, No. 1.

Huang, T. (2016b). Research object, main line and framework of socialist economics with Chinese characteristics, Marxism and Reality, No. 3.

Kaplan, R. S. \& Norton, D. P. (2000). The Strategy Focused Organization: How Balanced Scorecard Companies Thrive in the New Business Environment. Harvard Business School Press, Boston, MA.

Katukurunda, K. G. W. K., Yajid, S. M. A, Khatibi, A. and Azam, S. M. F. (2019). Students' Satisfaction towards Biosystems Technology; Does Programme Quality Matters? (Evidence from Sri Lankan Perspectives), European Journal of Open Education and Elearning Studies, 3 (2): 174-190

Kline, R. B. (2011). Principles and practice of structural equation modeling. New York, NY: Guilford.

Kothari, C. R. (2004). Research Methodology: Methods and Techniques. 2nd Edition, New Age International Publishers, New Delhi.

Kuruwitaarachchi, N., Yajid, S. M. A. Khatibi, A. and Azam, S. M. F. (2019). Enhance the use of Internet Based Advanced Communication Technologies in Small and Medium Scale Enterprises in Sri Lanka, European Journal of Social Sciences Studies, 3 (2): 44-57.

Li, K., Griffin, D., Yue, H., \& Zhao, L. (2011). National culture and capital structure decisions: Evidence from foreign joint ventures in China. Journal of International Business Studies, 42(4), 477-503. 
Li, K., Yue, H., \& Zhao, L. (2009). Ownership, institutions, and capital structure: Evidence from China. Journal of Comparative Economics, 37(3), 471-490.

Lisboa, I. (2017). Capital structure of exporter SMEs during the financial crisis: evidence from Portugal. European Journal of Management Studies, 22(1):25-49

Liu, M. M., Zhang, J. A., \& Hu, B. (2006). Domestic VCs versus foreign VCs: A close look at the Chinese venture capital industry. International Journal of Technology Management, 34(1-2), 161-184.

Lucey, B. M., \& Dowling, M. (2013). Cultural Behavioral Finance in Emerging Markets. Emerging Markets and the Global Economy: A Handbook, 327.

Luigi, P., \& Sorin, V. (2009). A Review of the Capital Structure Theories. Annals of Faculty of Economics, 3(1), 315-320.

Luther, C, Fortuin, L \& Wouters, M. (2005). Designing a performance measurement system: a case study. European Journal of Operational Research, 156 (2), 267- 286.

Maghfuriyah, A., Azam, S. M. F. and Shukri, S. (2019). Market Structure and Islamic Banking Performance in Indonesia: An Error Correction Model, Management Science Letters, 9 (9): 1407-1418.

Maxwell, S. E. \& Delaney, H. D. (2004). Designing Experiments and Analyzing Data. 2nd edition. Lawrence Erlbaum Associates.

Michaelas, N., Chittenden, F., \& Poutziouris, P. (1998). A model of capital structure decision making in small firms. Journal of small business and enterprise development, 5(3), 246-260.

Michaelas, N., Chittenden, F., \& Poutziouris, P. (1999). Financial policy and capital structure choice in UK SMEs: Empirical evidence from company panel data. Small business economics, 12(2), 113-130.

Miles, J., and Shevlin, M. (2001). Applying regression and correlation: A guide for students and researchers. London: Sage Publications Ltd.

Mira, F. S. (2002). On Capital Structure in the Small and Medium-sized Enterprises: The Spanish Case. Jean Monnet European Centre of Excellence, no.2, pp. 1-27.

Nguyen, H. N., Tham, J, Khatibi, A. and Azam, S. M. F. (2019). Enhancing the Capacity of Tax Authorities and its Impact on Transfer Pricing Activities of FDI Enterprises in Ha Noi, Ho Chi Minh, Dong Nai, and Binh Duong Province of Vietnam, Management Science Letters, 9 (8): 1299-1310

Norton, E. (1991). Capital structure and small growth firms. The Journal of Entrepreneurial Finance, 1(2), 161-177.

Norvaisiene, R. (2012). The Impact of Capital Structure on the Performance Efficiency of Baltic Listed Companies. Inzinerine Ekonomika-Engineering Economics, 23 (5), 505516.

Pallant, J. (2011). SPSS survival manual: A step by step guide to data analysis using SPSS. McGraw- Hill International.

Pambreni, Y., Khatibi, A., Azam, S. M. F. and Tham, J. (2019). The Influence of Total Quality Management toward Organization Performance, Management Science Letters, 9 (9): 1397-1406 
Pandey, I. M. (2004). Financial Management. London: Mordem Printers.

Paul, S., Whittam, G., \& Wyper, J. (2007). The pecking order hypothesis: Does it apply to start-up firms? Journal of Small Business and Enterprise Development, 14(1), 8-21.

Peel, M. J., \& Wilson, N. (1996). Working capital and financial management practices in the small firm sector. International Small Business Journal, 14(2), 52-68.

Peng, D. X., \& Lai, F. (2012). Using partial least squares in operations management research: a practical guideline and summary of past research. Journal of Operations Management, Vol. 30 No. 6, pp. 467-480.

Rachmawati, D., Shukri, S., Azam, S. M. F. and Khatibi, A. (2019). Factors Influencing Customers' Purchase Decision of Residential Property in Selangor, Malaysia, Management Science Letters, 9 (9): 1341-1348

Rajan, R. G., \& Zingales, L. (1995). What do we know about capital structure? Some evidence from international data. Journal of finance, 50(5), 1421-1460.

Rao, N. V., Mohamed Al-Yahyaee K. H., \& Syed, L. A. M. (2007). Capital structure and financial performance: Evidence from Oman. Indian Journal of Economics and Business, 6(1).

Reid G. C. (1996). Financial structure and the growing small firm: Theoretical underpinning and current evidence. Small Business Economics, 8(1): 1-7.

Riportella, C. C. \& Martínez, J. C. (2003). What Do We Know About the Financial Behavior of The Spanish SMEs? An Empirical Analysis. Business Economics, Series 08, Universidad Carlos III de Madrid.

Ross, S. A. (1977). The determination of financial structure: The incentive signaling approach. Bell Journal of Economics, 8(1), 23-40.

San, O. T. \& Heng, T. B. (2011). Capital Structure and Corporate Performance of Malaysian Construction Sector. International Journal of Humanities and Social Science, 1(2), 28-36.

Sapsford, R. (2007) Survey Research. 2nd Edition. Sage Publications, London.

Saunders, M., Lewis, P., \& Thornhill, A. (2009). Research Methods for Business Students. Harlow, England: Pearson Education.

Seifert, B. \& Gonenc, H. (2008). The international evidence on the pecking order hypothesis. Journal of Multinational Financial Management, vol. 18, pp. 244-260.

Sekaran, U. \& Bougie, R. (2016). Research Methods for Business: A Skill Building Approach. 7th Ed., New York, John Wiley \& Sons Ltd.

Shi, S. (2016). China Venture Group NEEQ year report (2015). Beijing: China Venture Institute.

Taylor R. (1990). Interpretation of the correlation coefficient: a basic review. Journal of Diagnostic Medical Sonography, 1: 35-39.

Tham, J., Yazid, M. S. A, Khatibi, A. A. and Azam, S. M. F. (2017). Internet and Data Security - Understanding Customer Perception on Trusting Virtual Banking Security in Malaysia, European Journal of Social Sciences Studies, 2 (7): 186-207 
Udriyah, U., Tham, J. and Azam, S. M. F. (2019). The Effects of Market Orientation and Innovation on Competitive Advantage and Business Performance of Textile SMEs, Management Science Letters, 9 (9): 1419-1428

Wang, R., Rafiq, M., Li, X. and Zheng, X. (2014). Entrepreneurial preparedness: an exploratory case study of Chinese private enterprises, International Journal of Entrepreneurial Behavior \& Research, Vol. 20 No. 4, pp. 351-274.

Yang, Z. Z., Tham, J. and Azam S. M. F. (2019). Negative Psychological Factors and Online Shopping Behaviour: A Review Among College Students' at Tongren City in China, European Journal of Management and Marketing Studies, 4 (4), pp.40-58.

Ying, Y, Albaity M. \& Zainir, F. (2016). Determinants of Capital Structure: A Comparison between Industrial and Consumer Sectors in China. Asian Journal of Business and Accounting, 9(2).

Yinxing, H. (2016). Building a theoretical system of socialist political economics with Chinese characteristics based on innovative theory, Economic Research Journal, No. 4.

Yu, Y., Luo, W., Lee, Y., \& Zhu, Q. (2014). Investment behaviour and performances of government-sponsored venture capitals. Economic Research Journal, (2), 32-46.

$\mathrm{Yu}, \mathrm{Z}$. (2016b). The development of political economics with Chinese characteristics, People's Daily, February 23.

Zhang, G. B. (2008). The choice of formal or informal finance: Evidence from Chengdu, China. China Economic Review, vol.19, no. 4, pp. 659-678.

Zhang, W., Gao, J., White, S., \& Vega, P. (2008). Venture capital and the financing of China's new technology firms. China's emergent political economy: Capitalism in the dragon's lair (pp. 60-82). New York, NY: Routledge.

Zhou, L., Chan, E. and Song, H. (2017). Social capital and entrepreneurial mobility in early-stage tourism development: a case from rural China, Tourism Management, Vol. 63, pp. 338-350.

Zikmund, W. G. (2003). Business Research Methods, 7th Edition. Thomson South Western, USA. 
Creative Commons licensing terms

Authors will retain copyright to their published articles agreeing that a Creative Commons Attribution 4.0 International License (CC BY 4.0) terms will be applied to their work. Under the terms of this license, no permission is required from the author(s) or publisher for members of the community to copy, distribute, transmit or adapt the article content, providing a proper, prominent and unambiguous attribution to the authors in a manner that makes clear that the materials are being reused under permission of a Creative Commons License. Views, opinions and conclusions expressed in this research article are views, opinions and conclusions of the author(s).Open Access Publishing Group and European Journal of Economic and Financial Research shall not be responsible or answerable for any loss, damage or liability caused in relation to/arising out of conflict of interests, copyright violations and inappropriate or inaccurate use of any kind content related or integrated on the research work. All the published works are meeting the Open Access Publishing requirements and can be freely accessed, shared, modified, distributed and used in educational, commercial and non-commercial purposes under a Creative Commons Attribution 4.0 International License (CC BY 4.0). 